\title{
Intervening in gun markets: an experiment to assess the impact of targeted gun-law messaging
}

\author{
Greg Ridgeway • Anthony A. Braga • George Tita • \\ Glenn L. Pierce
}

Published online: 27 August 2010

(C) The Author(s) 2010. This article is published with open access at Springerlink.com

\begin{abstract}
The objective of this study was to assess whether targeting new gun buyers with a public safety message aimed at improving gun law awareness can modify gun purchasers' behaviors. Between May 2007 and September 2008, 2,120 guns were purchased in two target neighborhoods of the City of Los Angeles. Starting in August 2007, gun buyers initiating transactions on odd-numbered days received a letter signed by prominent law enforcement officials, indicating that law enforcement had a record of their gun purchase and that the gun buyer should properly record future transfers of the gun. The letters arrived during buyers' 10-day waiting periods, before they could legally return to the store to collect their new gun. Subsequent gun records were extracted to assess the letter's effect on legal secondary sales, reports of stolen guns, and recovery of the gun in a crime. An intent-to-treat analysis was also conducted as a sensitivity check to remedy a lapse in the letter program between May and August 2007. The letter appears to have no effect on the legal transfer rate or on the short-term rate of guns subsequently turning up in a crime. However, we found that the rate at which guns are reported stolen for those who received the letter is more than twice the rate for those who did not receive the letter ( $p$ value $=0.01$ ). Those receiving the letter reported their gun stolen at a rate of 18 guns per 1,000 gun-years and those not receiving the letter reported their gun stolen at a rate of 7 guns per 1,000 gun-years. Of those receiving the letter, 1.9\% reported their gun stolen
\end{abstract}

G. Ridgeway $(\bowtie)$

RAND Corporation, Santa Monica, CA, USA

e-mail: gregr@rand.org

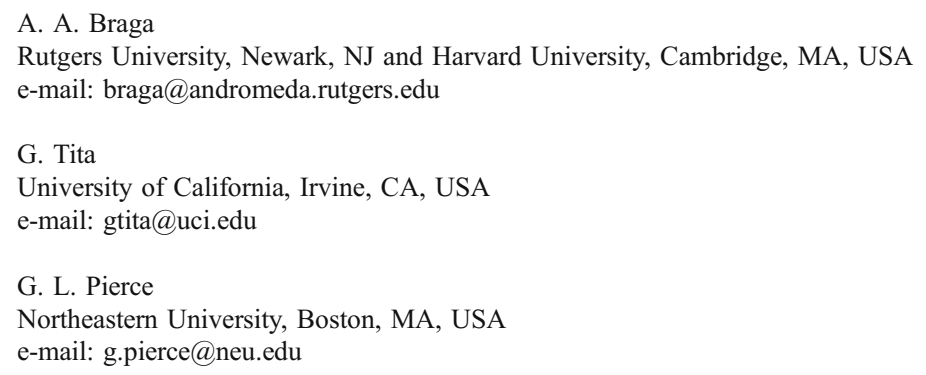


during the study period compared to $1.0 \%$ for those who did not receive the letter. The percentage of guns reported stolen in these neighborhoods is high, indicating a high rate of true gun theft, a regular practice of using stolen-gun reports to separate the gun buyer from future misuse of the gun, or some blend of both. Simple, targeted gun law awareness campaigns can modify new gun buyers' behaviors. Additional follow-up or modifications to this initiative might be needed to impact the rate at which guns enter the illegal gun market and ultimately are recovered in crimes.

Keywords Crime guns $\cdot$ Illegal gun markets $\cdot$ Stolen guns

\section{Introduction}

It is against federal law to knowingly transfer a firearm to those prohibited from possessing a firearm. California law further requires that all gun transfers be conducted at licensed dealers and that stolen guns need to be reported. Nevertheless, current research evidence suggests that illegal diversions from legitimate commerce and theft are important sources of guns for criminals (Braga et al. 2002). While there may be promising avenues to control gun theft and informal transfers, we do not yet know whether it is possible to shut down illegal pipelines of guns to criminals or what the costs of such a shutdown would be to legitimate purchasers. As the U.S. National Research Council's Committee to Improve Research Information and Data on Firearms concluded, answering these questions is essential in understanding whether market-based approaches can reduce criminal access to guns and lower gun violence (Wellford et al. 2005).

An interagency working group of law enforcement officials and academics collaborated on problem-oriented research to understand the workings of illegal gun markets in Los Angeles (Ridgeway et al. 2008). Participants included the U.S. Bureau of Alcohol, Tobacco, Firearms, and Explosives (ATF), California Department of Justice (CalDOJ), Los Angeles Police Department, Los Angeles City Attorney's Office, and others. The research suggested that one important flow of illegal guns to criminals in targeted areas involved legal purchasers who engaged in one or two "straw purchases" to provide guns to someone with a disqualifying criminal record. The interagency working group then developed a plan to deter legal purchasers from acquiring guns for criminals in the targeted areas.

Among other strategies, the working group developed a mail campaign to target new gun buyers before they had an opportunity to transfer their firearm to someone else. They developed a letter that arrives in the new gun buyer's mailbox during the 10-day waiting period and reminds gun buyers of their legal obligations. The letter indicates that the firearm purchase has been documented and that, should it be used in a crime, the gun can and will be traced back to them as the first legal purchaser (see Appendix).

The mail campaign was premised on the idea that straw purchasers can be deterred from illegally transferring guns. The working group posited that, because these individuals had no prior arrests or convictions that prohibited them from making a legal firearm purchase, they represented a target population that could be deterred easily. Specific-deterrence perspectives suggest that such individuals are more likely than those with criminal histories to be deterred by the prospect of increased risks for criminal sanctions (see Paternoster 1987, and Nagin 1998, for a 
review). A letter that clearly informs the straw purchaser of the risk of sanctions might generate that specific deterrence.

\section{Data sources}

In California, all firearm purchases must be conducted through a Federal Firearm Licensee (FFL) ${ }^{1}$ and CalDOJ maintains a permanent record of those sales in the Automated Firearms System (AFS). To initiate the sale the gun dealer completes a Dealer Record of Sale (DROS), recording information about the gun, such as the make, model, manufacturer, serial number, caliber, contact information for the purchaser, and the date of the transaction. ${ }^{2}$ AFS maintains a permanent record of subsequent events related to the gun. This includes reports of the gun's loss or theft, subsequent transfers of the gun, and the gun turning up as a "crime gun," a gun recovered by law enforcement that was in the possession of a prohibited possessor (felons, some violent misdemeanants, youths, those adjudicated mentally ill, and individuals with restraining orders) or recovered in connection with a crime.

The working group identified two geographically distinct areas, LAPD's Devonshire and the 77th Street policing districts, for inclusion in the letter program. The 77th Street area is $12 \mathrm{mi}^{2}$ with 175,000 residents, and Devonshire is nearly $54 \mathrm{mi}^{2}$, with a total population of 250,000 . Both areas have large numbers of residents who are legally buying guns that are ultimately being recovered as crime guns in the possession of others.

Regardless of where in California the gun transaction occurred, if a purchaser's residential ZIP code was in either Devonshire or the 77th Street area $^{3}$ then CalDOJ sent the Los Angeles City Attorney's Office details of the gun transactions on the following day. Between May 2007 and September 2008, 2,120 gun purchases were initiated in the two target areas. Starting in August 2007, letters were mailed to those potential gun buyers who initiated their gun purchase on an odd-numbered day. Note that this means that we have data on guns purchased between May 2007 and August 2007, but no letters were sent during this period. The study period ended in June 2009 by which time 878 gun buyers received a letter. The control cases consist of those who did not receive the letter.

Because the letter was not sent on odd-numbered days between May and August 2007 due to a lapse in the letter program following the election of a new California attorney general, there is a validity threat that sales before August 2007 differ from those after August 2007. An analysis that simply excludes the 410 guns purchased during this period, however, would result in an underpowered analysis (power $<0.10)$. Instead we also conducted, as a sensitivity check, an analysis that considered guns purchased on any oddnumbered day, including those purchased between May and August 2007 as treated cases, and all guns purchased on even numbered days as control cases. This is an intent-to-treat analysis, common in randomized trials with lapses in compliance, that preserves some

\footnotetext{
${ }^{1}$ Calif. Penal Code $\$ \S 12072[a][5], 12072[\mathrm{~d}]$

${ }^{2}$ Calif. Penal Code $\$ 12077[\mathrm{~b}]$

${ }^{3}$ We defined the 77th Street area as ZIP codes 90001, 90003, 90037, 90043, 90044, 90047, and 90062 and Devonshire as ZIP codes 91401, 91402, 91403, 91405, 91406, 91411, 91423, and 91436, excluding the parts that extend beyond the city limits, beyond the jurisdiction of the Los Angeles city attorney.
} 
power (since it supplies 202 control cases to improve precision of the control group rates) but biases the treatment effect toward 0 , resulting in a more conservative assessment.

For each gun we computed an exposure time, the duration of time the gun was owned by the gun purchaser. For $94 \%$ of the gun buyers this was the time between their purchase date and the end of the study period. For the remainder, this was the time between their purchase date and when they transferred their gun, reported their gun stolen, or law enforcement recovered their gun. The exposure time ranged between a few days and 25 months, but $80 \%$ of the exposure times were between 6 and 23 months.

To measure the effect of the letter, we estimated the rate ratio, RR. The rate ratio computes the rate at which incidents occur per year of exposure for those who received the letter relative to the incidence rate per year of exposure for those who did not receive the letter. For example, the RR for the letter's effect on reports of stolen guns is:

$$
R R=\frac{\frac{\text { number of stolen guns with letter }}{\text { total years of exposure for those with the letter }}}{\frac{\text { number of stolen guns with no letter }}{\text { total years of exposure for those without the letter }}}
$$

The RR can be estimated with Poisson regression.

The purchase location is predictive of a gun's future (Wintemute et al. 2005). Since letters were sent on odd-numbered days, the purchase location is uncorrelated with receipt of the letter. Therefore, including dealer indicators reduces the model's residual error and improves the precision of the RR estimator without biasing the treatment effect estimate. We included indicator variables for the four largest gun dealers, each with more than 100 transactions during the study period. The model has the form:

$$
\begin{aligned}
& Y_{i} \sim \operatorname{Poisson}\left(\lambda_{i}\right), \log \left(\lambda_{i}\right)=\log (\text { exposure time })+\beta_{0}+\beta_{1} \text { letter }+\beta_{2} F F L 1 \\
& +\beta_{3} F F L 2+\beta_{4} F F L 3+\beta_{5} F F L 4
\end{aligned}
$$

where $Y_{i}$ is the outcome indicator (i.e., stolen, crime gun) and the four FFL variables are indicators for a gun being sold from a specific dealer. $\exp \left(\beta_{1}\right)$ equals RR.

\section{Results}

We found that those who received the letter reported their guns stolen at a significantly higher rate $(p$ value $=0.01)$. Table 1 shows the calculation details. The adjusted rates account for the purchase location. The rate ratio of 2.6 indicates that those who were sent the letter reported their gun stolen at more than twice the rate of those who did not receive the letter. Stolen guns were reported on average 6 months after purchase; those receiving the letter reported the gun stolen 20 days sooner on average, but there are too few stolen guns for the difference to be statistically significant.

As noted previously, between May 2007 and August 2007, we collected data on the guns, but the letter distribution lapsed until August 2007. As a sensitivity check, we conducted an intent-to-treat analysis that regarded all odd days, even those before August 2007, as "letter" days and found that the significant finding still held $(p$ value $=0.05)$.

We also posited that guns purchased by buyers targeted with the letter would be less likely to become crime guns, but the rates at which they became crime guns 
Table 1 Relative risks of stolen guns and crime guns

\begin{tabular}{|c|c|c|c|c|}
\hline & \multicolumn{2}{|l|}{ Stolen guns } & \multicolumn{2}{|l|}{ Crime guns } \\
\hline & Letter & No letter & Letter & No letter \\
\hline Number of transactions & 878 & 1,242 & 878 & 1,242 \\
\hline Total exposure time (years) & 983.4 & 1644.7 & 983.4 & 1644.7 \\
\hline Number of stolen/crime guns & 17 & 12 & 16 & 26 \\
\hline $\begin{array}{l}\text { Unadjusted rate (stolen/crime guns per } 1,000 \\
\text { guns per year) }\end{array}$ & 17.3 & 7.3 & 16.3 & 15.8 \\
\hline \multirow[t]{2}{*}{ Unadjusted rate ratio ( $95 \%$ confidence interval) } & $2.4(1.1,5.0)$ & & $1.0(0.5,1.9)$ & \\
\hline & $p=0.02$ & & $p=0.93$ & \\
\hline $\begin{array}{l}\text { Adjusted rate (stolen/crime guns per 1,000 } \\
\text { guns per year) }\end{array}$ & 18.2 & 7.1 & 17.2 & 15.6 \\
\hline \multirow[t]{2}{*}{ Adjusted rate ratio ( $95 \%$ confidence interval) } & $2.6(1.2,5.5)$ & & $1.1(0.6,2.1)$ & \\
\hline & $p=0.01$ & & $p=0.76$ & \\
\hline
\end{tabular}

were statistically indistinguishable: 17 per 1,000 guns per year for letter recipients and 16 per 1,000 guns per year for those not receiving the letter. Roughly $1 \%$ of the guns were recovered as crime guns during the study period. Our ability to detect an impact on the likelihood of becoming crime guns may be limited by the 22-month post-intervention period. In 2005 and 2006, only 13\% of crime guns in California were recovered within 2 years of the first retail sale.

\section{Discussion}

The results of this study suggest that in some respects, legal gun purchasers do respond to market-based interventions. Gun-law messaging increased the likelihood that new gun owners reported thefts of recently purchased firearms. Enhanced reporting of gun theft will improve our understanding of the role of theft in supplying criminals with firearms. Official data systems that record stolen guns are well known to be limited by the problem that many stolen guns are never reported to the authorities (Kennedy et al. 1996) and much of what we know about stolen guns is derived from one-time or occasional surveys of criminals (e.g., Wright and Rossi 1994).

Unfortunately, the more complete reporting of theft and the notification to recent purchasers that they would be held responsible for making legal subsequent transfers did not impact the short-term likelihood that these guns were recovered in crime by law enforcement agencies. The available data do not allow us to determine whether recently purchased guns that were reported stolen were all actually stolen or, as some in the working group suggested, some proportion were falsely being reported as stolen to break the paper trail between the straw purchaser and the actual criminal owner of the gun. It is possible that the gun letter initiative could have some longer-term impacts as particular neighborhoods are saturated with letters and casual straw purchasers decide not to make additional purchases. Given the short-term impacts on gun-purchaser behavior, longerterm study of the gun letter initiative seems to be warranted. 
Acknowledgements Peter Shutan, assistant supervising attorney for the gang division of the Los Angeles city attorney's office, coordinated the letter campaign with the California Department of Justice's Firearm Division. Paul Seave, director of the Office of Gang and Youth Violence Policy for California, was instrumental in engaging key parties and facilitating the letter program. Denise Stearns at ATF's Southern California Regional Crime Gun Center analyzed and recorded the histories of each of the guns in the study.

Funding National Institute of Justice grant 2001-IJ-CS-0028 funded this research.

Open Access This article is distributed under the terms of the Creative Commons Attribution Noncommercial License which permits any noncommercial use, distribution, and reproduction in any medium, provided the original author(s) and source are credited.

\section{Appendix: The gun letter}

Office of the Attorney General for the State of

California Office of the Los Angeles City Attorney

Los Angeles Police Department

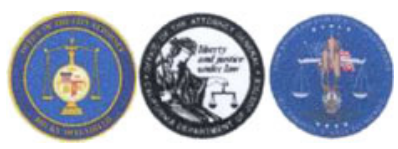

Name

Address

Dear Mr./Ms. Name,

As you know, gun violence is a serious problem in Los Angeles. We understand that you have recently purchased a gun. It is important that we all do our part to store guns safely and keep guns out of the hands of kids and criminals. We are working in collaboration with the federal program called Project Safe Neighborhood (PSN).

As partners in keeping the streets safe in your neighborhood we want to remind you of your obligations as a gun owner.

If you ever decide to sell or give your gun to someone, you must complete a "Dealer Record of Sale" (DROS) form. These forms can be obtained and completed at any gun store. Remember, it is a crime to transfer a gun to anyone without first filling out this form.

If the police recover a gun that was involved in a crime, the Los Angeles City Attorney will prosecute the gun's previous owner if that owner did not complete the "Dealer Record of Sale" form. Please make sure you go to a firearms dealer and fill out that form if you want to sell or give away your firearm.

You can help us make Los Angeles a safer community by preventing your gun from ending up in the wrong hands.

Thank you,

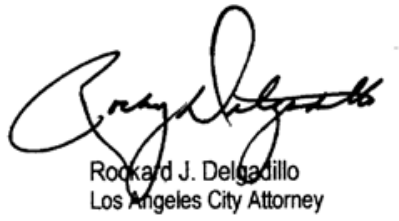

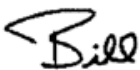

Bill Lockyer, Attorney General State of California

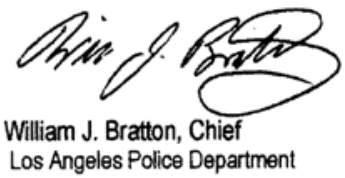

Los Angeles Police Department 


\section{References}

Braga, A. A., Cook, P. J., Kennedy, D. M., \& Moore, M. H. (2002). The illegal supply of firearms. In M. Tonry (Ed.), Crime and justice: A review of research, 29 (pp. 319-352). Chicago: University of Chicago Press.

Kennedy, D. M., Piehl, A. M., \& Braga, A. A. (1996). Youth violence in Boston: Gun markets, serious youth offenders, and a use-reduction strategy. Law and Contemporary Problems, 59, 147-196.

Nagin, D. S. (1998). Criminal deterrence research at the outset of the twenty-first century. In M. Tonry (Ed.), Crime and justice: A review of research, 23 (pp. 1-42). Chicago: University of Chicago Press.

Paternoster, R. (1987). The deterrent effect of the perceived certainty and severity of punishment: a review of the evidence and issues. Justice Q, 4, 173-218.

Ridgeway, G., Pierce, G. L., Braga, A. A., Tita, G., Wintemute, G., \& Roberts, W. (2008). Strategies for disrupting illegal firearm markets: A case study of Los Angeles. TR-512-NIJ Santa Monica: RAND Corporation. Available at http://www.rand.org/pubs/technical_reports/TR512/.

Wellford, C., Pepper, J. V., \& Petrie, C. (Eds.). (2005). Firearms and violence: A critical review. Committee to Improve Research Information and Data on Firearms. Washington, DC: National Academies Press.

Wintemute, G. J., Cook, P. J., \& Wright, M. A. (2005). Risk factors among handgun retailers for frequent and disproportionate sales of guns used in violent and firearm related crimes. Injury Prevention, 11, 357-363.

Wright, J. D., \& Rossi, P. H. (1994). Armed and considered dangerous: A survey of felons and their firearms (2nd ed.). Hawthorne: Aldine de Gruyter.

Greg Ridgeway $\mathrm{PhD}$ is the Director of RAND's Safety and Justice Research Program and Director of RAND's Center on Quality Policing, charged with managing RAND's portfolio of work on policing, crime prevention, courts, corrections, and public and occupational safety. In 2007 he was recognized by the American Statistical Association for innovative analysis of policing issues. In 2005, he received a commendation from the ATF Los Angeles Field Division and the Attorney General of California for "Contributions to Reducing Firearms Related Crimes in Los Angeles."

Anthony A. Braga $\mathrm{PhD}$ is a Professor in the School of Criminal Justice at Rutgers University and a Senior Research Fellow in the Program in Criminal Justice Policy and Management at Harvard University's John F. Kennedy School of Government. He is also a Fellow of the Academy of Experimental Criminology and former Visiting Fellow at the U.S. National Institute of Justice. Dr. Braga was a recipient of the U.S. Attorney General's Award for Outstanding Contributions to Community Partnerships for Public Safety (2009) and was the U.S. Department of Justice Project Safe Neighborhoods Outstanding Service by a Research Partner Award (2010).

George Tita PhD is an Associate Professor in the Department of Criminology, Law and Society at the University of California - Irvine. His research is anchored in the community and crime literature with a special focus on the causes and correlates of interpersonal violence. Much of his policy research has been devoted to issues surrounding gun violence including the design and implementation of effective strategies aimed at reducing gun violence as well as study of illegal gun markets in Los Angeles. Currently, Dr. Tita is working with an interdisciplinary team of social scientists and mathematician at UCLA studying the formation and dissipation of crime hot spots.

Glenn L. Pierce PhD is a Principal Research Scientist and the Acting Director of the Institute for Security and Public Policy at the College of Criminal Justice at Northeastern University. Dr. Pierce has conducted research on a broad range of social and economic issues. His current research focuses on crime and firearms violence, intergroup conflict and criminal justice and intelligence information systems. 